\title{
QAGUPUBLICATIONS
}

Journal of Geophysical Research: Earth Surface

Supporting Information for

\section{Fast response of Amazon rivers to Quaternary climate cycles}

Samuel L. Goldberg' ${ }^{1}$, Morgan J. Schmidt ${ }^{1}$, J. Taylor Perron ${ }^{1}$

'Department of Earth, Atmospheric, and Planetary Sciences, Massachusetts Institute ofTechnology, 77 Massachusetts Ave., Cambridge MA 02139

\section{Contents of this file}

Table S1

\section{Introduction}

- This table describes the observational and calculated data that are represented by Figure 5. Data sources are described in Section 2.2. 
Table S1: Database of Amazon tributaries.

\begin{tabular}{|c|c|c|c|c|c|c|c|c|c|c|c|c|}
\hline Station & River & $\begin{array}{l}\text { Drainage } \\
\text { area }\left(10^{3}\right. \\
\left.\mathbf{k m}^{2}\right)\end{array}$ & $\underset{\left(m^{3} / s\right)}{Q w}$ & $\begin{array}{c}\text { Qs } \\
\left(10^{6}\right. \\
\left.\mathrm{m}^{3} / \mathrm{yr}\right)\end{array}$ & $\begin{array}{c}\text { Slope } \\
(-) \\
\left(\times 10^{-5}\right)\end{array}$ & $\begin{array}{l}\text { Floodplain } \\
\text { width (km) }\end{array}$ & $\begin{array}{c}\text { Sinuosity } \\
(-)\end{array}$ & $\begin{array}{c}\text { Alluvial } \\
\text { length } \\
(\mathbf{k m})\end{array}$ & $\begin{array}{l}\text { Diffusivity } \\
\left(10^{6} \mathrm{~m}^{2} / \mathrm{yr}\right)\end{array}$ & $\begin{array}{c}\text { Diffusion } \\
\text { time } \\
\left(10^{3} \mathrm{yr}\right)\end{array}$ & $\begin{array}{l}\text { Propagation } \\
\text { length }(\mathbf{k m})\end{array}$ & Setting \\
\hline Palmeiras do Javari & Javari & 12 & 640 & 0.46 & 8 & 5 & 1.7 & 1000 & 6.92 & 144.4 & 438 & Foreland \\
\hline Teresina & Solimoes & 980 & 44000 & 151 & 3 & 15 & 1.2 & 4900 & 473.70 & 50.7 & 6279 & Andes \\
\hline Sao Paulo de Olivenca & Solimoes & 990 & 47000 & 122 & 3 & 20 & 1.2 & 4900 & 383.86 & 62.5 & 4880 & Andes \\
\hline Santo Antonio do Ica & Solimoes & 1100 & 55000 & 167 & 3 & 30 & 1.2 & 4900 & 328.22 & 73.2 & 4668 & Andes \\
\hline Cruzeiro do Sul & Jurua & 39 & 910 & 4.44 & 10 & 12 & 1.5 & 2600 & 4.83 & 1400.7 & 737 & Foreland \\
\hline Eirunepe-Montante & Jurua & 77 & 1800 & 3.16 & 5 & 15 & 2.2 & 2600 & 10.95 & 617.1 & 953 & Foreland \\
\hline Gaviao & Jurua & 160 & 4800 & 12.3 & 4 & 20 & 2.0 & 2600 & 29.12 & 232.1 & 1734 & Foreland \\
\hline Vila Bittencourt & Japura & 197 & 13720 & 9.91 & 5 & 8 & 1.2 & 2000 & 198.30 & 20.2 & 1706 & Andes \\
\hline Itapeua & Solimoes & 1800 & 84000 & 115 & 3 & 20 & 1.1 & 4900 & 853.37 & 28.1 & 4543 & Andes \\
\hline Rio Branco & Acre & 23 & 330 & 1.38 & 9 & 6 & 1.3 & 570 & 1.73 & 187.5 & 571 & Foreland \\
\hline Seringal Fortaleza & Purus & 150 & 3700 & 25.3 & 5 & 20 & 2.1 & 3000 & 23.03 & 390.9 & 2281 & Foreland \\
\hline Labrea & Purus & 220 & 5500 & 16.6 & 4 & 20 & 2.1 & 3000 & 38.30 & 235.0 & 2064 & Foreland \\
\hline Bacaba & Cuniua & 38 & 1490 & 0.52 & 8 & 9 & 1.5 & 700 & 12.06 & 40.6 & 325 & Craton \\
\hline Aruma-Jusante & Purus & 360 & 11000 & 6.72 & 4 & 25 & 1.7 & 3000 & 67.13 & 134.1 & 1058 & Foreland \\
\hline Manacapuru & Solimoes & 2100 & 99000 & 115 & 1 & 30 & 1.1 & 4900 & 418.59 & 57.4 & 6419 & Andes \\
\hline Cucui & Negro & 62 & 4840 & 0.32 & 3 & 2 & 1.1 & 1900 & 12.72 & 283.8 & 754 & Craton \\
\hline Taraqua & Uaupes & 45 & 2760 & 0.22 & 10 & 3 & 1.2 & 560 & 81.57 & 3.8 & 290 & Foreland \\
\hline Jalauaca & Demini & 23 & 530 & 0.1 & 10 & 5 & 1.5 & 430 & 0.46 & 402.8 & 170 & Foreland \\
\hline Fe e Esperanca & Mucajai & 14 & 280 & 0.11 & 10 & 3 & 1.3 & 140 & 0.25 & 77.0 & 216 & Craton \\
\hline Caracarai & Branco & 130 & 2900 & 1.12 & 7 & 10 & 1.1 & 575 & 1.80 & 183.4 & 416 & Craton \\
\hline Pontes e Lacerda & Guapore & 3 & 60 & 0.02 & 80 & 1 & 1.1 & 760 & 0.18 & 3185.1 & 45 & Craton \\
\hline Pimenteiras & Guapore & 54 & 530 & 0.05 & 6 & 3 & 1.3 & 760 & 0.51 & 1124.5 & 179 & Craton \\
\hline Pedras Negras & Guapore & 110 & 910 & 0.05 & 7 & 8 & 1.4 & 760 & 0.50 & 1145.9 & 114 & Craton \\
\hline Guajara-Mirim & Mamore & 589 & 8400 & 11.8 & 10 & 12 & 1.2 & 1700 & 89.56 & 32.3 & 1076 & Andes \\
\hline Porto Velho & Madeira & 950 & 19000 & 96.6 & 7 & 10 & 1.2 & 3250 & 303.19 & 34.8 & 4178 & Andes \\
\hline Jiparana & Jiparana & 33 & 720 & 0.27 & 30 & 1 & 1.2 & 680 & 5.04 & 91.8 & 326 & Craton \\
\hline Prainha (Velha) & Aripuana & 109 & 3380 & 0.84 & 20 & 2 & 1.2 & 850 & 20.91 & 34.6 & 497 & Craton \\
\hline Fazenda Vista Alegre & Madeira & 1300 & 31000 & 76 & 5 & 7 & 1.2 & 3250 & 779.04 & 13.6 & 5051 & Andes \\
\hline Obidos & Amazonas & 4600 & 170000 & 171 & 1 & 40 & 1.1 & 4900 & 705.87 & 34.0 & 6783 & Andes \\
\hline Barragem-Conj. 04 & Curua-Una & 14 & 180 & 0.02 & 9 & 1 & 1.3 & 460 & 0.47 & 453.2 & 200 & Craton \\
\hline
\end{tabular}

